Editorial

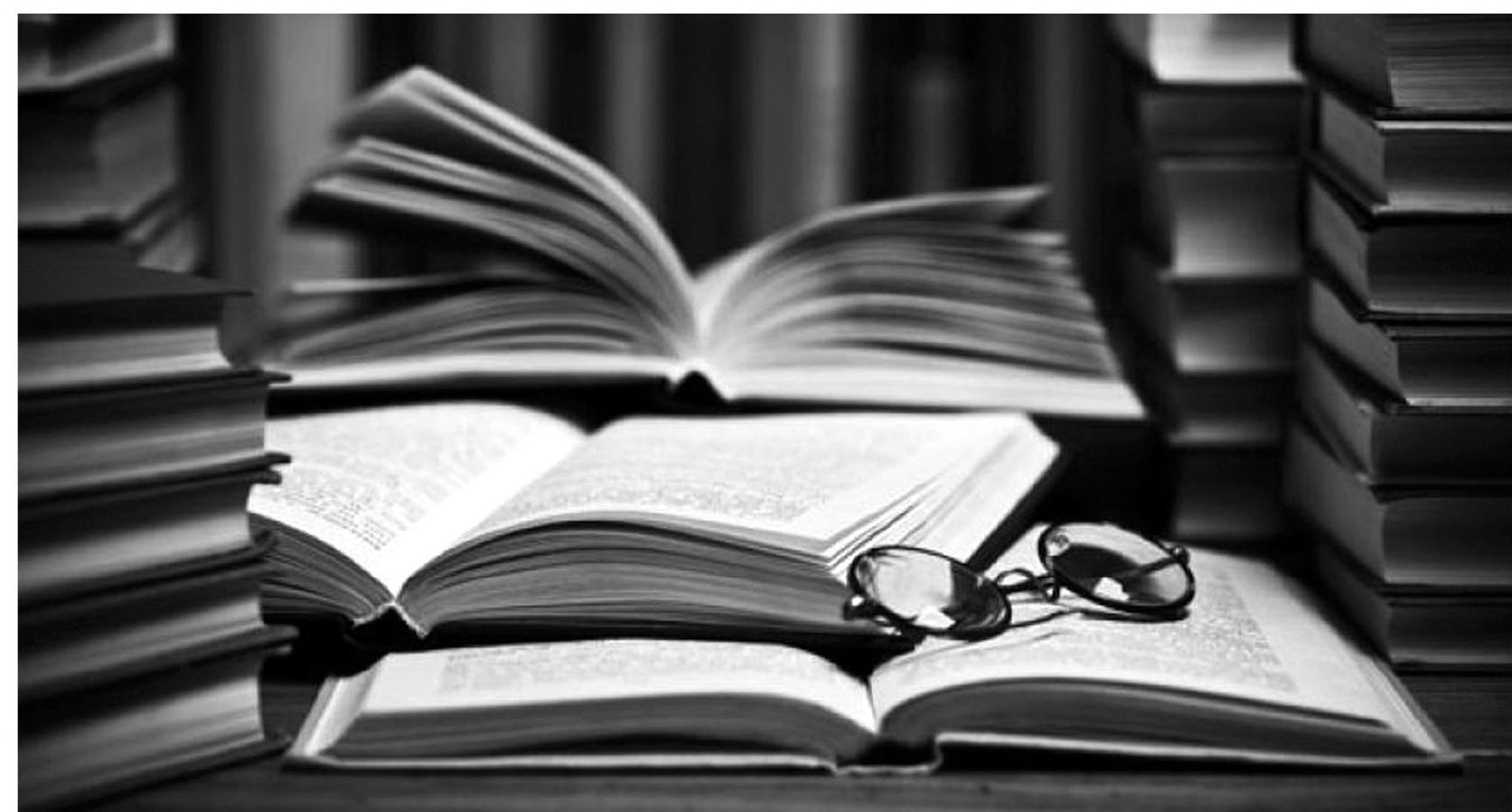





\section{VERITAS LIBERAT NOBIS}

En días pasados se celebró el día del maestro en México. La celebración tiene su origen en la conmemoración del 15 de mayo de 1950 cuando el papa Pío XII nombró a San Juan Bautista de La Salle, -sacerdote francés- como el Patrono universal de los educadores por haber fundado la Congregación de los Hermanos de las Escuelas Cristianas, institución de enseñanza laica para maestros dedicados a la formación de los niños y jóvenes pobres y huérfanos cuya expansión se dio en 85 países del mundo.

Educar tal como lo reconoce la Organización de las Naciones Unidas para la Educación, la Ciencia y la Cultura es un proceso sistemático de transmisión de hábitos, costumbres, valores y conocimiento que va de generación en generación. La educación es fundamental para alcanzar la cohesión social mediante la transmisión de valores tales como la verdad, la equidad, la justicia, el amor por el otro, la libertad y las leyes, es así que se reconoce que la educación transforma vidas y resulta indispensable para consolidar la paz, erradicar la pobreza e impulsar el desarrollo sostenible. En tal sentido la educación es considerada un Derecho Humano para TODOS a lo largo de TODA la vida.

En mayo del 2015 en Incheon, República de Corea se celebró el Foro Mundial sobre la Educación, en el cual se reafirmó la visión de un movimiento mundial en pro de la educación para todos, que se puso en marcha desde 1990 en Jomtien, Tailandia y que se reiteró en Dakar, Senegal en el año 2000, cuyos compromisos son a favor de los Objetivos de Desarrollo Sostenible reconociendose la función esencial que desempeña la educación como un derecho humano y su interrelación con otros derechos humanos, por lo que se convierte así en uno de los principales motores del desarrollo de la sociedad.

Por su parte en la Cumbre de Oslo, Noruega de 2015 sobre Educación para el Desarrollo y la Tercera Conferencia Internacional sobre Financiación para el Desarrollo en Addis Abeba, Etiopía de 2015, se declaró que es necesario incrementar considerablemente la financiación para conseguir este Objetivo 
de Desarrollo Sostenible, se afirmó que la educación requiere una financiación sostenida, innovadora y bien orientada, así como acuerdos eficaces de aplicación, por lo que con tal fin se creó una comisión de alto nivel: La Comisión Internacional sobre la Financiación de las oportunidades para la Educación mundial, como un primer paso firme para redinamizar la promoción de la inversión en educación y acabar con el déficit actual de financiación en buena parte del mundo.

En tal sentido se fijaron indicadores internacionales de referencia, por ejemplo asignar por lo menos entre el $4 \%$ y el $6 \%$ del producto interno bruto (PIB) a la educación y asignar por lo menos el $15 \%$ y el $20 \%$ del gasto público a la educación. La propuesta es que los países deberán incrementar el gasto público en favor de la educación y asignar una mayor porción del presupuesto nacional a la educación, además se estableció que fortalecer la eficiencia y la rendición de cuentas logrará que se garantice que el recurso llegue a las aulas de clase.

Por su parte el 4o Objetivo de Desarrollo Sostenible de la agenda 2030 de la ONU establece: Garantizar una educación de calidad, inclusiva y equitativa, y promover las oportunidades de aprendizaje permanente para todos, para tal efecto se fijan 7 metas: 1. Educación primaria y secundaria universal. 2. Desarrollo en la primera infancia y educación preescolar universal. 3. Acceso igualitario a la educación técnica/profesional y superior. 4. Habilidades adecuadas para un trabajo decente. 5 . Igualdad entre los sexos e inclusión. 6. Alfabetización universal de la juventud. 7. Educación de la ciudadanía para el desarrollo sostenible y se señalan tres medios de ejecución: a) Entornos de aprendizaje eficaces. b) Becas. c) Maestros y educadores.

Es interesante observar como en esta política global sobre la educación el papel de los maestros es fundamental para alcanzar un desarrollo sostenible, se requiere centrar los esfuerzos en dignificar el papel del maestro, empoderándolo, motivándolo y cualificándolo profesionalmente, brindándole todo el apoyo necesario para dotarlo de recursos y mediante la cooperación internacional se formen profesores calificados, con lo cual se podrá alcanzar la equidad en la educación. 
En efecto, el papel de los docentes y educadores es fundamental en todas las fases de la educación; desde la formulación de programas de estudio, la planeación de cursos, la aplicación de métodos de enseñanza hasta el seguimiento de los procesos educativos, en definitiva son los maestros quienes aseguran que los alumnos aprenden, ellos crean dentro de las aulas una realidad que va desde el marco de las políticas públicas a la práctica del día a día, cumpliendo con ello el anhelo de la inclusión, la calidad y la equidad.

Paulo Freire nos hablaba de ese contenido ideológico - político - pedagógico entendido como una práctica de la libertad, que se puede relacionar con la concepción del amor en Platón. Así la educación es en esencia un acto amoroso que potencializa la vida del otro, al incidir en el pleno y auténtico desarrollo de los alumnos, la educación se constituye como un verdadero desarrollo de la libertad, del diálogo y de la comunicación.

El rol que juegan los maestros en el desarrollo requiere de compromiso ético y antropológico, debe ponderarse la coherencia entre el discurso y la práctica, fortalecerse una dinámica en donde no sólo se transmiten conocimeintos sino que se trata de problematizar los contenidos, analizar la realidad, confrontar al educando por medio del diálogo crítico y lo más importante, enseñar al alumno a pensar críticamente los contenidos. Es así como podemos afirmar que la educación es una práctica de la libertad, en donde las palabras forman diálogos que crean, comprometen y transforman.

El educador establece dentro del aula un compromiso por el estudio y la investigación en donde la dinamica es transformadora para el alumno. Indudablemente la comunidad internacional tiene un compromiso con la educación integradora de calidad, inclusión y equidad para todos los niños, jóvenes y adultos a lo largo de toda la vida, con el objetivo de alcanzar la transformación, es así que se cumple la máxima de que la verdad os hará libres.

Verano 2021

Dra. Silvia Patricia López González 


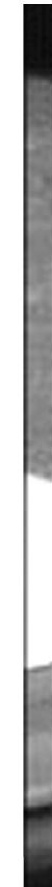

